\title{
PENGARUH KETERLIBATAN SUPLIER DAN KONSUMEN SERTA INOVASI PRODUK TERHADAP PERFORMA PRODUK BARU DI PT. PUSPA PHARMA
}

\author{
Rey Hagai Yheri \\ Program Studi Magister Manajemen Universitas Tarumanagara \\ reyhagai@gmail.com \\ Yanuar \\ Program Studi Magister Manajemen Universitas Tarumanagara
}

\begin{abstract}
This study aims to find out how the influence of several factors studied on the performance of new products so that the advantages and disadvantages of PT. Puspa Pharma. Some of these factors are the suppression of brand profiles, internal coordination, competitororiented, product innovation, and the involvement of consumers and suppliers. The data used in this study are primary data, which came from the results of questionnaire collection as many as 96 respondents at PT. Puspa Pharma. This research takes place from March 2018 to November 2018. The data analysis method used in this study is the Partial Least Square (PLS) analysis method that uses SmartPLS software version 3.0. The results of the study show that the performance of new products at PT. Puspa Pharma is more influenced by the involvement of suppliers and consumers compared to product innovation. Where the involvement of suppliers and consumers is supported by two important factors namely competitor-oriented and product innovation itself. Whereas internal coordination and suppression of brand profiles do not affect the involvement of suppliers and consumers.
\end{abstract}

\begin{abstract}
Abstrak : Penelitian ini bertujuan mengetahui bagaimana pengaruh dari beberapa faktor yang diteliti terhadap performa produk baru sehingga dapat diketahui kelebihan dan kekurangan di PT. Puspa Pharma. Beberapa faktor tersebut adalah penekanan profil merk, koordinasi internal, berorientasi terhadap kompetitor, inovasi produk, dan keterlibatan konsumen dan suplier. Data yang digunakan dalam penelitian ini adalah data primer, yang berasal dari hasil pengumpulan kuisioner sebanyak 96 responden di PT. Puspa Pharma. Penelitian ini berlangsung dari bulan Maret 2018 sampai dengan November 2018. Metode analisis data yang digunakan dalam penelitian ini adalah metode analisa Partial Least Square dengan software SmartPLS versi 3.0.Hasil penelitian menunjukan bahwa performa produk baru di PT. Puspa Pharma lebih dipengaruhi oleh keterlibatan suplier dan konsumen dibandingkan dengan inovasi produk. Keterlibatan suplier dan konsumen tersebut didukung oleh dua faktor penting yaitu berorientasi terhadap kompetitor dan inovasi produk itu sendiri. Sedangkan untuk koordinasi internal dan penekanan profil merk tidak mempengaruhi keterlibatan suplier dan konsumen.
\end{abstract}

Keywords : Involvement, Innovation, Competitor, Coordination, Brand 


\section{PENDAHULUAN}

\section{Latar Belakang}

Perusahaan adalah suatu organisasi dimana sumber daya (input) dasar seperti bahan dan tenaga kerja dikelola serta diproses untuk menghasilkan barang atau jasa (output) kepada pelanggan untuk memenuhi kebutuhan dan memperoleh keuntungan bagi perusahaan. Keuntungan yang diperoleh oleh perusahaan tergantung dari produk yang dijualnya apakah produk tersebut dapat memenuhi dan memuaskan kebutuhan pelanggan. Pengembangan produk baru melibatkan berbagai kegiatan yang kompleks dan saling berkaitan seperti menilai peluang terhadap ide-ide produk baru, memasukkan persyaratan produk ke dalam spesifikasi produk jadi, dan meluncurkan produk tersebut ke pasaran. Pada pengembangan produk baru, perusahaan biasanya memperoleh pengetahuan dan sumber daya eksternal dari keterlibatan pemasok dan pelanggan. Hal Ini membantu meningkatkan kinerja operasional perusahaan, kemampuan kolektif, dan juga kemampuan berinovasi. Namun, keterlibatan tersebut dipengaruhi oleh banyak faktor secara internal dan secara eksternal, termasuk penerimaan produk, kekuatan dan kepercayaan, kebergantungan rantai pasokan, dan juga sistem informasi.

\section{Tujuan Penelitian}

Tujuan dari penelitian ini untuk mengetahui bagaimana pengaruh dari beberapa variabel yang diteliti terhadap performa produk baru sehingga dapat diketahui kelebihan dan kekurangan di PT. Puspa Pharma yang diharapkan dapat menjadi pedoman strategi dalam meningkatkan performa produk baru.

\section{TINJAUAN PUSTAKA}

\section{Keterlibatan Suplier dan Konsumen}

Keterlibatan Suplier didefinisikan sebagai partisipasi langsung dari suplier pada saat proses pengembangan produk baru (Ragatz et al., 1997) Keterlibatan konsumen didefinisikan sebagai partisipasi langsung konsumen dalam merancang dan mengembangkan berbagai tahapan dari pengembangan produk baru, dimana konsumen terikat langsung dalam kegiatan penyelesaian masalah dan pengembangan produk jadi dengan perusahaan. (Feng et al., 2010). Terdapat tiga indikator untuk mengukur keterlibatan suplier dan konsumen yaitu:

- Pentingnya suplier dan konsumen memberikan ide atau pendapat tentang ciri-ciri produk baru dalam pengembangan produk baru. (Svendsen et al., 2009)

- Pentingnya suplier atau konsumen memberikan ide bahan baku produk dalam pengembangan produk baru (Svendsen et al., 2009)

- Pentingnya konsumen mengkomunikasikan kebutuhan konsumen dalam mengembangkan produk. (Svendsen et al., 2009)

\section{Penekanan Profil Merk}

Penekanan profil merk ditunjukan sebagai sejauh mana perusahaan mengedepankan atau mengemukakan profil dari brand dan reputasi perusahaannya dalam aktivitas marketing dan 
penjualan. (Ghosh and John., 1999).Terdapat dua indikator yang terdapat dalam variabel penekanan profil merk yaitu nama brand dan reputasi perusahaan (Svendsen et al., 2009)

\section{Koordinasi Internal}

Koordinasi internal didefinisikan sebagai mekanisme integrasi interal yang majemuk diantaranya team lintas fungsi, kerja sama, keterlibatan karyawan, rekayasa enginering, tim khusus, dan tim yang diperdayakan dapat memberikan rekomedasi pada fase yang berbeda dalam pengembangan produk baru. (Griffin et al., 2002). Terdapat 4 indikator yang dapat menjelaskan koordinasi internal yaitu rapat rutin antar departemen, integrasi data antar departemen, koordinasi bersama proses desain dan proses pengembangan, dan koordinasi bersama kegiatan launching produ baru (Lau et.al., 2011)

\section{Berorientasi Terhadap Kompetitor}

Orientasi terhadap kompetitor didefinisikan sebagai kemampuan dan keinginan untuk mendapatkan informasi tentang aksi kompetitor terhadap target pasar dan meresponi terhadap hal tersebut (Narver and Slater, 1990). Terdapat dua indikator yang dapat mengukur berorientasi terhadap kompetitor yaitu mendapatkan informasi tentang apa yang dilakukan oleh kompetitor utama dan melakukan penyesuaian terhadap strategi penjualan yang dilakukan oleh kompetitor utama (Svendsen et al., 2009)

\section{Inovasi Produk}

Secara general disimpulkan sebagai ukuran dari ketidakberlanjutan dalam marketing dan atau faktor teknologi dalam level industri atau perusahaan. (Calantone et al., 2006) sebuah pemaparan literatur secara komperhensif menunjukan bahwa penting untuk mempertimbangkan dari sudut pandang marketing dan teknologi, sama juga seperti dari level makro dan level mikro, pada saat mengidentifikasi inovasi. Terdapat tiga indikator untuk mengukur inovasi produk yaitu: produk lebih baru dibandingkan produk sebelumnya, produk dianggap inovasi baru oleh pelanggan, produk pertama kali dipasaran (Lau et al., 2011)

\section{Performa Produk Baru}

Performa pengembangan produk baru menunjukan sebagaimana baik perusahaan melakukan proses pengembangan ide suatu produk baru untuk menjadi produk komersial. Terdapat dua indikator untuk mengukur performa produk baru yaitu produk baru mencapai target penjualan dan produk baru mempunyai selisih keuntungan atau selisih margin yang baik (Lau et al., 2011)

\section{Model Penelitian}

Pada model penelitian ini garis $\mathrm{H} 1, \mathrm{H} 2, \mathrm{H} 3$, dan $\mathrm{H} 4$ menunjukan pengaruh langsung terhadap variabel keterlibatan suplier dan konsumen. Sedangkan garis H5 dan H6 menunjukan pengaruh langsung terhadap variabel performa produk baru. 


\section{Gambar 1. Model Penelitian}

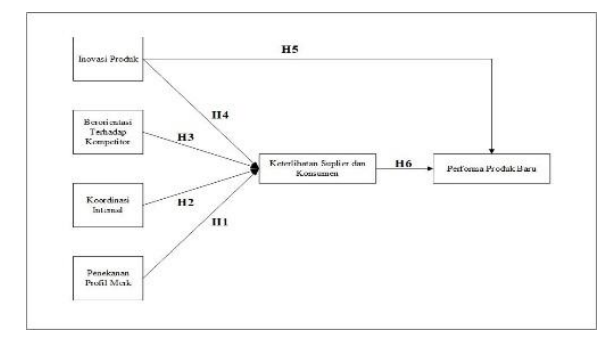

\section{Hipotesis Penelitian}

Dari hubungan antara variabel independen dengan variabel dependen di atas, maka diperoleh hipotesis penelitian sebagai berikut:

H1: Efek penekanan profil merk terhadap keterlibatan konsumen dan suplier

H2: Efek koordinasi internal terhadap keterlibatan konsumen dan suplier

H3: Efek berorientasi terhadap kompetitor terhadap keterlibatan konsumen dan suplier

H4: Efek inovasi produk terhadap keterlibatan konsumen dan suplier

H5: Efek inovasi produk terhadap performa produk baru

H6: Efek keterlibatan konsumen terhadap performa produk baru

\section{METODE PENELITIAN}

Dalam penelitian ini teknik pengambilan sampel yang digunakan adalah purposive sampling. Purposive sampling adalah teknik penentuan sampel dengan pertimbangan-pertimbangan tertentu (Sanusi, 2011). Dalam penelitian ini kriteria sampel yang dimaksud adalah karyawan PT. Puspa Pharma yang bekerja di divisi supply chain, purchasing, research and development, marketing, dan sales. Jumlah populasi diketahui secara pasti, maka perhitungan jumlah sampel yang digunakan dalam penelitian ini disesuaikan dengan metode analisi yang digunakan yaitu Structural Equation Model (SEM). Dalam metode SEM, jumlah sampel yang dibutuhkan paling sedikit 5 kali jumlah indikator variabel (Ferdinan, 2014). Adapun jumlah indikator dalam penelitian ini sebanyak 16 indikator, sehingga minimal dibutuhkan 16 x 5 atau 80 sampel. Penelitian ini menggunakan kuesioner sebagai sumber data primer yang terstruktur mengenai penekanan profil merk, koordinasi internal, berorientasi terhadap kompetitor, inovasi produk, keterlibatan suplier dan konsumen, dan performa produk baru. Pernyataan - pernyataan yang akan dilampirkan dalam kuesioner berupa pernyataan lima poin skala Likert. Skala dalam pernyataan pada kuisioner dapat diklasifikasikan sebagai berikut:

1. Sangat baik/sangat setuju/sangat puas/sangat penting nilainya 5

2. Baik/setuju/puas/penting

3. Cukup baik/cukup setuju/cukup puas/cukup penting

nilainya 4

4. Kurang baik/kurang setuju/kurang puas/kurang penting

nilainya 3

5. Tidak baik/tidak setuju/tidak puas/tidak penting

nilainya 2

nilainya 1

Data yang diperoleh dari kuisioner tersebut dianalisis dengan menggunakan metode analisis Structural Equation Model (SEM) dengan program smart PLS versi 3.0 untuk memenuhi tujuan penelitian. 


\section{HASIL DAN PEMBAHASAN}

\section{Pengukuran Model (Outer Model)}

\section{Pengujian Convergent Validity}

Convergent validity dari measurement model dilihat dari korelasi antara skor indikator dengan skor variabelnya. Variabel dianggap valid jika memiliki nilai AVE diatas 0,5 atau memperlihatkan seluruh outer loading dimensi dalam suatu variabel memiliki nilai loading factor > 0,5 sehingga hasil tersebut dapat menyimpulkan bahwa pengukuran tersebut memenuhi kriteria validitas konvergen (Chin dalam Kalnadi 2013)

Gambar 2. Output Path Diagram (loading factor)

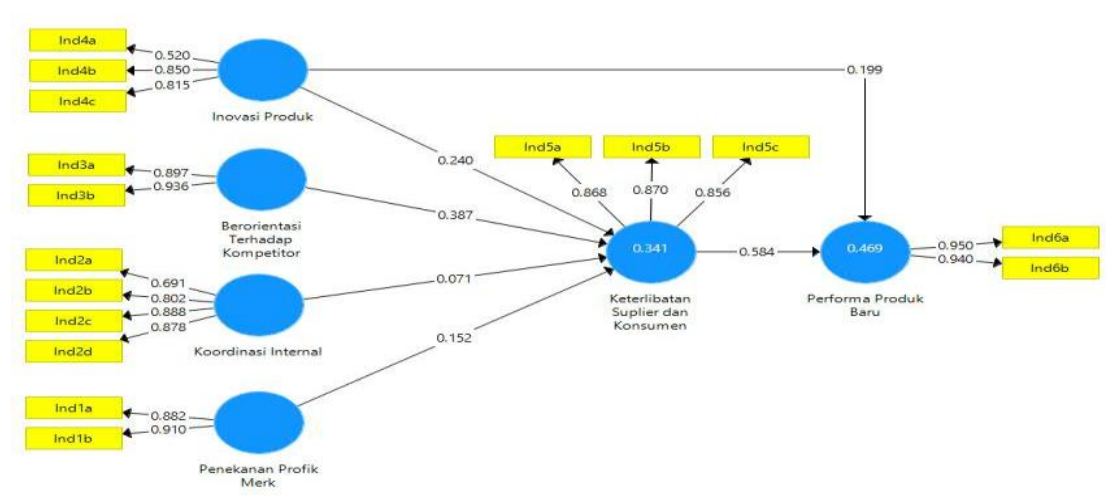

Tabel 1. Hasil Avarage Variance Extracted (AVE)

\begin{tabular}{|l|c|}
\hline \multicolumn{1}{|c|}{ Variabel } & AVE \\
\hline Berorientasi Terhadap Kompetitor & 0.840 \\
\hline Inovasi Produk & 0.553 \\
\hline Keterlibatan Suplier dan Konsumen & 0.748 \\
\hline Koordinasi Internal & 0.670 \\
\hline Penekanan Profik Merk & 0.803 \\
\hline Performa Produk Baru & 0.894 \\
\hline
\end{tabular}

Dari tabel di atas, terlihat hasil AVE yang diperoleh pada semua variabel adalah di atas (>) 0.5. Sehingga hasil tersebut memenuhi persyaratan pertama dari parameter Avarage Variance Extracted (AVE).

\section{Pengujian Internal Consistency / Pengujian Reliabilitas}

Jika melihat Tabel 2 dibawah, terlihat uji kehandalan (reliability) dapat terlihat dari nilai cronbach's alpha dan nilai composite reliability. Dimana dengan nilai composite reliability harus diatas 0.70 dan diperkuat dengan nilai cronbach's alpha yang diatas 0.60 dan maka semua variabel yang terdapat dalam penelitian ini dapat dikatakan reliabel atau memiliki 
kehandalan yang baik. Oleh karena itu, tahap pengujian internal consistency dapat disimpulkan telah terpenuhi untuk semua variabelnya.

Tabel 2. Quality Criteria.

\begin{tabular}{|l|c|c|c|c|}
\hline \multicolumn{1}{|c|}{ Variabel } & AVE & Composite Reliability & R Square & Cronbach's Alpha \\
\hline Berorientasi Terhadap Kompetitor & 0.840 & 0.913 & 0.841 & 0.812 \\
\hline Inovasi Produk & 0.553 & 0.781 & 0.614 & 0.671 \\
\hline Keterlibatan Suplier dan Konsumen & 0.748 & 0.899 & 0.835 & 0.832 \\
\hline Koordinasi Internal & 0.670 & 0.889 & 0.883 & 0.838 \\
\hline Penekanan Profik Merk & 0.803 & 0.891 & 0.764 & 0.755 \\
\hline Performa Produk Baru & 0.894 & 0.944 & 0.886 & 0.881 \\
\hline
\end{tabular}

\section{Pengujian Discriminant Validity}

Pada tabel 2 bisa terlihat bahwa nilai AVE seluruh variabel diatas 0.50 sehingga syarat pertama telah terpenuhi. Untuk syarat yang kedua, Pada tabel 3 di bawah, merupakan nilai akar kuadrat AVE (angka dengan tanda "*” yang berada pada posisi diagonal) setiap variabel harus lebih besar dari nilai korelasi variabel lainnya (angka yang posisinya dalam satu baris dan satu kolom dengan AVE variabel yang bersesuaian). Dengan hasil tersebut, model penelitian ini sudah memenuhi syarat terhadap discriminant validity.

\section{Tabel 3. Korelasi Latent Variable}

\begin{tabular}{|l|c|c|c|c|c|c|}
\hline Variabel & BTK & IP & KSdK & KI & PPM & PPB \\
\hline BTK & $\mathbf{0 . 9 1 7} *$ & & & & & \\
\hline IP & 0.221 & $\mathbf{0 . 7 4 4} *$ & & & & \\
\hline KSdK & 0.479 & 0.381 & $\mathbf{0 . 8 6 5} *$ & & & \\
\hline KI & 0.310 & 0.324 & 0.326 & $\mathbf{0 . 8 1 8} *$ & & \\
\hline PPM & 0.111 & 0.214 & 0.273 & 0.373 & $\mathbf{0 . 8 9 6} *$ & \\
\hline PPB & 0.419 & 0.421 & 0.660 & 0.358 & 0.195 & $\mathbf{0 . 9 4 5}$ \\
\hline
\end{tabular}

\section{Analisis Structural Model (Inner Model)}

Inner model dievaluasi dengan menggunakan R-square untuk konstruk dependen uji-t dan signifikansi koefisien parameter jalur struktural

Tabel 4. Nilai $R$-square

\begin{tabular}{|l|c|}
\hline \multicolumn{1}{|c|}{ Variabel } & R Square \\
\hline Keterlibatan Suplier dan Konsumen & 0.341 \\
\hline Performa Produk Baru & 0.469 \\
\hline
\end{tabular}

Dari tabel 4 di atas dapat disimpulkan bahwa variabel keterlibatan suplier dan konsumen dapat dijelaskan dengan variabel inovasi produk, berorientasi terhadap kompetitor, koordinasi internal, dan penekanan profil merk sebesar 0.341 atau $34.1 \%$ dan variabel performa produk baru dapat dijelaskan dengan variabel keterlibatan suplier dan konsumen serta inovasi produk sebesar 0.469 atau $46.9 \%$.

\section{Analisis Hipotesis}

Uji hipotesis dilakukan dengan melihat t-statistik dan $P$ Values. Nilai t-statistik menunjukan tingkatan pengaruh konstruk sedangkan $P$ Values menentukan signifikan atau tidaknya 
hubungan antara variabel dependen dan variabel independen. Hipotesis dapat diterima apabila $P$ Values lebih kecil $(<)$ dari 0.005 dan T statistik lebih besar 1.80. Berikut adalah tabel yang menunjukan hasil diterima atau tidaknya semua hipotesis yang terdapat penelitian ini.

Tabel 5. Hasil Hipotesis

\begin{tabular}{|c|c|c|c|}
\hline Hipotesis & T Statistics (|O/STDEV $\mid$ ) & P Values & Hasil \\
\hline Hipotesis 1 & 1.755 & 0.080 & Ditolak \\
\hline Hipotesis 2 & 0.657 & 0.511 & Ditolak \\
\hline Hipotesis 3 & 3.823 & 0.000 & Diterima \\
\hline Hipotesis 4 & 2.262 & 0.024 & Diterima \\
\hline Hipotesis 5 & 2.515 & 0.012 & Diterima \\
\hline Hipotesis 6 & 10.028 & 0.000 & Diterima \\
\hline
\end{tabular}

\section{KESIMPULAN dan SARAN}

\section{Kesimpulan}

Pada penelitian ini dapat disimpulkan bahwa inovasi produk dan berorientasi terhadap kompetitor mempunyai pengaruh terhadap keterlibatan suplier dan konsumen. Sedangkan koordinasi internal dan penekanan profil merk tidak mempengaruhi keterlibatan suplier dan konsumen. Pada performa produk baru di PT. Puspa Pharma lebih dipengaruhi oleh keterlibatan suplier dan konsumen dibandingkan dengan inovasi produk. Diperoleh juga keterlibatan suplier dan konsumen dapat memediasi pengaruh inovasi produk, koordinasi internal, berorientasi terhadap kompetitor dan penekanan profil merk terhadap performa produk baru.

\section{Saran}

Inovasi produk PT. Puspa Pharma dapat ditingkatkan kembali dengan cara menghasilkan produk yang lebih baru dibandingkan produk sebelumnya. Sedangkan untuk berorientasi terhadap kompetitor dapat ditingkatkan kembali dengan cara lebih sering untuk mendapatkan informasi tentang apa yang dilakukan oleh kompetitor utama. Kemudian perlu dilakukannya pembenahan pada koordinasi internal yang terjadi di PT. Puspa Pharma. Pembenahan koordinasi internal dapat diutamakan pada peningkatan rapat rutin dan integrasi data antar departemen. Selain dari itu, PT. Puspa pharma juga perlu memperbaiki branding terhadap beberapa produk yang dimiliki. Hal tersebut dikarenakan penekanan profil merk di PT. Puspa Pharma tidak berpengaruh secara positif terhadap performa produk baru.

\section{REFERENSI}

Calantone, R.J., Chan, K. and Cui, A.S. (2006), "Decomposing product innovativeness and its effects on new product success", Journal of Product Innovation Management, Vol. 23, pp. 408-21.

Feng, T., Sun, L. and Zhang, Y. (2010), "The effects of customer and supplier involvement on competitive advantage: an empirical study in China”, Industrial Marketing Management, Vol. 39 No. 8, pp. 1384-94

Ghosh, M. and John, G. (1999), "Governance value analysis and marketing strategy”,Journal of Marketing, Vol. 63, Special issue, pp. 131-45 
Griffin, A. (2002), "Product development cycle time for business-to-business products", Industrial Marketing Management, Vol. 31, pp. 291-304.

Lau, A.K.W., Yam, R.C.M. and Tang, E.P.Y. (2010), "Supply chain integration and product modularity: an empirical study of product performance for selected Hong Kong manufacturing industries", International Journal of Operations and Production Management, Vol. 30 No. 1, pp. 20-56.

Narver, J.C. and Slater, S.F. (1990), "The effect of a market orientation on business profitability", Journal of Marketing, Vol. 54 No. 4, pp. 20-35.

Ragatz, G.L., Handfield, R.B. and Scannell, T.V. (1997), "Success factors for integrating suppliers into new product development", The Journal of Product Innovation Management, Vol. 14, pp. 190-202.

Svendsen, M.F; Haugland, S.A; Gronhaug, K; Hammervoll,T( 2011) "Marketing strategy and customer involvement in product development", European Journal of Marketing, Vol. 45 No. 4, pp. 513-530

Zirger, B.J. and Maidique, M.A. (1990), “A model of new product development: an empirical test”, Management Science, Vol. 36 No. 7, pp. 867-83. 
